\title{
FAKTOR-FAKTOR YANG BERHUBUNGAN DENGAN KEJADIAN TBC PARU DI WILAYAH KERJA PUSKESMAS BOLANGITANG
}

\author{
Sabirin B. Syukur ${ }^{1}$, Abdul Wahab Pakaya² \\ *Email : $\underline{\text { sabi_syukur@rocketmail.com }}$ \\ 1) Staf Dosen Ilmu Keperawatan Universitas Muhammadiyah Gorontalo \\ ${ }^{2}$ Staf Dosen Ilmu Keperawatan Universitas Muhammadiyah Gorontalo
}

\begin{abstract}
ABSTRAK
The proportion of patients with smear-positive pulmonary TB in 2012 that 141 people (1:56\%) of the total population were found smear-positive and amounted to 130 people $(1.44 \%)$ of the total population. From the data Bolangitang Health Center in 2012 it is known that there is a population of 9,027 souls $189(2.09 \%)$ were estimated economic suspected pulmonary TB and the suspected when examined totaled 180 people (1.99\%). While in 2013 the number of TB patients increased again that 157 people $(1: 59 \%)$ of the total population. Formulation of the problem ie what are the factors associated with the incidence of pulmonary tuberculosis in Puskesmas Bolangitang Mongondow Bolaang North In 2013? The purpose of the study to determine the factors associated with the incidence of pulmonary tuberculosis in Puskesmas Bolangitang Bolaang North Mongondow. The research design used in this study is the design of the study is descriptive and analytical research methods research is conducted with the main objective to create a picture / relationship about a situation objectively. The survey results revealed that the value of alpha chi square 38.000 with $\alpha=$ $0.000>0.05$ means that there is a relationship between age and the incidence of pulmonary tuberculosis. Chi-square value of 18,661 with a significant level of $\alpha=0.000>0.05$ means that there is a relationship between poverty and the incidence of pulmonary tuberculosis. Chi-square value of 16,765 with a significant level of $\alpha=0.000>0.05$ means that there is a relationship between poverty and the incidence of pulmonary tuberculosis. Based on the results of research and discussion, it can be concluded that age, poverty and the environment associated with the incidence of pulmonary tuberculosis in Puskesmas Bolangitang Bolaang North Mongondow.
\end{abstract}

Keywords: Age, Poverty, Environment, pulmonary TB 
Jurnal Zaitun

Universitas Muhammadiyah Gorontalo

\section{PENDAHULUAN}

Penyakit Tuberkulosis paru masih merupakan masalah kesehatan masyarakat dunia. Penyakit tuberkulosis paru banyak menyerang usia kerja produktif, kebanyakan dari kelompok sosial ekonomi rendah dan berpendidikan rendah. Meningkatnya kasus HIV/AIDS yang menurunkan daya tubuh juga menyebabkan meningkatnya kembali penyakit TBC di negara-negara yang sudah berhasil mengendalikan penyakit. Banyak penderita yang tidak berhasil disembuhkan, penderita dengan basil tahan asam (BTA) positif berisiko menularkan penyakit pada orang lainnya. Tahun 2003, WHO mencanangkan kedaruratan global penyakit TBC. Diperkirakan setiap tahun ada 9 juta penderita TBC baru dengan kematian 3 juta orang. 95\% penderita TBC berada di negara berkembang dan beban terbesar terutama adalah di Asia Tenggara. Di negara-negara berkembang kematian ini merupakan $25 \%$ dari kematian penyakit yang sebenarnya dapat diadakan pencegahan (Depkes, 2010). Indonesia merupakan negara terpadat nomor 4 di dunia dengan jumlah penduduk 255 juta pada tahun 2012, penyakit TBC menduduki tempat ke 3 terbesar didunia setelah China dan India (Depkes 2012). Dari hasil survey kesehatan rumah tangga, penyakit TBC merupakan penyebab kematian nomor tiga terbesar setelah penyakit Kardiovasculer dan penyakit saluran pernapasan atas (ISPA) pada semua golongan umur dan penyebab penyakit nomor satu pada kelompok penyakit infeksi (Depkes 2012). WHO memperkirakan bahwa di Indonesia setiap tahun terjadi 583.000 kasus untuk semua jenis TBC dan 282.000 kasus baru dengan BTA (+). Prevalensi kasus TBCC-Paru BTA (+) diperkirakan 715.000 dengan kematian sekitar 140.000 atau secara kasar diperkirakan setiap 100.000 penduduk Indonesia terdapat 130 penderita TBCParu baru dengan BTA (+) dan menyerang sebagian besar usia produktif, kelompok ekonomi lemah dan berpendidikan rendah (Depkes 2012).

Dalam upaya penanggulangan TBC di Indonesia telah ditetapkan tujuan program pemberantasan yang meliputi tujuan jangka panjang yaitu menurunkan angka kesakitan, kematian dan penularan TBC dengan cara memutuskan rantai penularan sehingga penyakit TBC tidak lagi menjadi masalah kesehatan masyarakat di Indonesia, dan tujuan jangka pendek yaitu menyembuhkan minimal $85 \%$ penderita baru BTA (+) yang ditemukan, tercapinya cakupan penemuan penderita secara bertahap sampai dengan tahun 2007, 70\% mencegah timbulnya resistensi obat TBC di masyarakat (Depkes, 1999). Dari hasil prasurvey yang dilakukan peneliti di Dinas Kesehatan Kabupaten Bolaang Mongondow Utara diketahui bahwa pada tahun 2012 jumlah penderita TBC yakni 122 jiwa (1.32\%) dari jumlah penduduk dan yang ditemukan BTA positif berjumlah 98 jiwa $(1,03 \%)$ dari jumlah penduduk. Pada tahun 2013, penyakit TB Paru berada pada rangking 3 (tiga) dari 10 (sepuluh) penyakit yang paling banyak 
penderitanya. Proporsi penderita TB Paru BTA Positif tahun 2012 yakni 141 jiwa $(1.56 \%)$ dari jumlah penduduk dan yang ditemukan BTA Positif berjumlah 130 jiwa $(1,44 \%)$ dari jumlah penduduk. Dari data Puskesmas Bolangitang tahun 2012 diketahui bahwa dari 9.027 jumlah penduduk terdapat 189 jiwa $(2,09 \%)$ yang terestimasi suspek TB paru dan yang suspek saat diperiksa berjumlah 180 jiwa (1,99\%). Sedangkan pada tahun 2014 jumlah penderita TBC meningkat lagi yakni 157 jiwa (1.59\%) dari jumlah penduduk.

\section{METODOLOGI PENELITIAN}

Tempat dan Waktu Penelitian

Penelitian ini dilaksanakan di wilayah kerja Puskesmas Bolangitang Kabupaten Bolaang Mongondow Utara. Proses pengumpulan data awal hingga penyusunan skripsi dalam penelitian ini membutuhkan waktu selama 4 (empat) bulan yakni sejak bulan Oktober 2015 sampai Januari 2016.

\section{Desain Penelitian}

Desain penelitian yang digunakan adalah penelitian deskriptif analitik yaitu metode penelitian yang dilakukan dengan tujuan utama untuk membuat gambaran/hubungan tentang suatu keadaan secara objektif. Peneliti mencoba mencari hubungan antar variabel independen dan dependen, kemudian melakukan analisis terhadap data yang terkumpul untuk mencari hubungan antar variabel disebut dengan penelitian analitik. Rancangan penelitian analitik yang digunakan adalah rancangan penelitia cross sectional yakni penelitian epidemiologik yang dikerjakan di bidang kesehatan dan kedokteran (Sumantri, 2011).

\section{Populasi danSampel}

Populasi adalah keseluruha unit analisis yang karakteristiknya akan diduga (Hastono dan Sabri, 2006:177). Populasi dalam penelitian ini adalah penderita TB paru di wilayah kerja Puskesmas Bolangitang Kabupaten Bolaang Mongondow Utara yang berjumlah 180 orang. Sampel dalam penelitian ini adalah bagian dari populasi yang diambil dengan cara persentase. Menurut Arikunto (2003) bahwa jika populasi lebih dari 100 maka dapat diambil 5\%, 10\% dan 20\% dari jumlah populasi. Dalam penelitian ini sampel diambil sebesar $21 \%$ dari jumlah populasi sebagai berikut.

Populasi $=180$ orang

Persentase $=21 \%$

Sampel $=180$ orang $\times 21 \%=37.8=$ 38 (dibulatkan)

Jadi sampel dalam penelitian ini berjumlah 38 orang

Analisa Univariat

Teknik analisis data yang digunakan dalam penelitian ini yakni analisis univariat dengan cara dipersentasekan. Analisa univariat digunakan untuk mengetahui persentase identitas responden ditinjau dari jenis kelamin, usia dan pendidikan, persentase data responden seperti status gizi, pengetahuan dan kepadatan hunian rumah. Setelah didapat hasil persentase kemudian hasil persentase dimasukkan dalam tabel tabulasi data.

\section{Analisis Bivariat}

Melihat adanya pengaruh variabel, yaitu dengan menggunakan analisis bivariate, untuk mengetahui faktor- 
faktor yang berhubungan dengan kejadian TBC paru di Wilayah Kerja Puskesmas Bolangitang Kabupaten Bolaang Mongondow Utara Tahun 2013 dengan menggunakan uji ChiSquare

\section{HASIL PENELITIAN}

1. Karateristik Responden

Tabel 1.

Distribusi Responden Menurut Jenis Kelamin di wilayah kerja Puskesmas Bolangitang

Tabel 1 menunjukkan bahwa dari 38 responden menurut jenis kelamin, yang

\begin{tabular}{ccc}
\hline Tingkat Pendidikan & Jumlah Responden & $\%$ \\
\hline SD & 10 & 26 \\
SMP & 18 & 47 \\
SMA & 9 & 24 \\
Perguruan Tinggi & 1 & 3 \\
Total & 38 & 100 \\
\hline
\end{tabular}

tertinggi adalah jenis kelamin laki-laki sebanyak 25 orang $(66 \%)$ dan yang terendah adalah jenis

Tabel 2.

Distribusi Responden Menurut Pendidikan di wilayah kerja Puskesmas Bolangitang Sumber : Data Primer 2016

Berdasarkan data pada tabel 4.2 di atas dapat dijelaskan bahwa dari 38 responden paling banyak berpendidikan SMP yakni berjumlah 18 orang $(47 \%)$ sedangkan paling sedikit berpendidikan sampai Perguruan Tinggi yang berjumlah 1 orang $(3 \%)$.

\section{Analisis Univariat}

Data univariat dalam penelitian ini adalah variabel penelitian yang meliputi umur, kemiskinan, lingkungan dan TB Paru. Data univariat akan digambarkan dalam bentuk tabel yang dapat dilihat di bawah ini.

\begin{tabular}{lll}
\hline Jenis Kelamin & N & $\%$ \\
\hline Laki-laki & 25 & 66,0 \\
Perempuan & 13 & 34,0 \\
\hline
\end{tabular}

Tabel 3

\begin{tabular}{|c|c|c|c|c|}
\hline No & Variabel & Kategori & Frekuensi & $\%$ \\
\hline 1. & TB Paru & $\begin{array}{ll}\text { - } & \text { TB Paru + } \\
\text { - TB Paru - }\end{array}$ & $\begin{array}{l}28 \\
10\end{array}$ & 74 \\
\hline 2. & Umur & $\begin{array}{l}-\quad<55 \\
-\quad>55\end{array}$ & $\begin{array}{l}28 \\
10\end{array}$ & 74 \\
\hline 3. & Kemiskinan & $\begin{array}{l}\text { - Prasejahtera } \\
\text { - Sejahtera } 1\end{array}$ & $\begin{array}{l}22 \\
16\end{array}$ & 58 \\
\hline 4. & Lingkungan & $\begin{array}{l}\text { - Lingkungan } \\
\text { kotor } \\
\text { - Lingkungan } \\
\text { bersih }\end{array}$ & $\begin{array}{l}21 \\
17\end{array}$ & 55 \\
\hline
\end{tabular}

Sumber : Data Primer 2016

a. TB Paru

Mencermati data pada tabel di atas dapat dijelaskan bahwa dari 38 responden paling banyak mengalami TB paru + yakni berjumlah 28 orang (74\%) 
sedangkan yang mengidap TB paru - berjumlah 10 orang (26\%).

b. Umur

Berdasarkan tabel data univariat menunjukkan bahwa dari 38 responden sebagian besar berumur produktif < 55 tahun yakni berjumlah 28 orang $(74 \%)$ sedangkan yang berusia $>55$ tahun berjumlah 10 orang (26\%).

c. Kemiskinan

Sehubungan dengan data pada tabel di atas dapat dijelaskan bahwa dari 38 responden yang paling banyak adalah prasejahtera yang berjumlah 22 orang (58\%) dan responden dengan tingkat sejahtera 1 berjumlah 16 orang (42\%).

d. Lingkungan

Mencermati data pada tabel di atas dapat dijelaskan bahwa dari 38 responden paling banyak mengalami TB paru + yakni berjumlah 28 orang (74\%) sedangkan yang mengidap TB paru - berjumlah 10 orang (26\%).

\section{Analisis Bivariat}

Data bivariat dilakukan untuk menganalisis hubungan dua variabel. Dalam penelitian ini akan dianalisa hubungan antara umur, kemiskinan dan lingkungan dengan TB Paru. Penelitian uji bivariat diukur dengan menggunakan uji chi-square dengan tingkat kemaknaan 5\%. Berikut adalah hasil analisa bivariat antara variabel penelitian. a. Analisa hubungan umur dengan kejadian TB di wilayah kerja Puskesmas Bolangitang

Tabel 4

Hubungan Umur dengan TB Paru

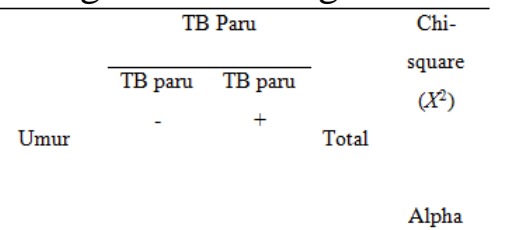

(a)

\begin{tabular}{|c|c|c|c|c|}
\hline $\begin{array}{c}\text { Produktif } \\
<55\end{array}$ & 0 & 28 & 28 & 38.000 \\
\hline Tidak & & & & \\
\hline Produktif & 10 & 0 & 10 & \\
\hline$>55$ & & & & 0.000 \\
\hline Total & 10 & 28 & 38 & \\
\hline
\end{tabular}

Sumber : Data Primer 2016

Sehubungan dengan data pada tabel di atas dapat dijelaskan bahwa dari 38 responden paling banyak berumur produktif dan mengalami TB paru + yakni berjumlah 28 orang. Dari hasil analisa diperoleh nilai chi square 38.000 dengan alpha $\alpha=0.000<0.05$ artinya bahwa terdapat hubungan antara umur dengan kejadian TB paru. Sehingga tolak $\mathrm{H}_{0}$ dan menerima $\mathrm{H}_{1}$ yakni terdapat hubungan antara umur dengan kejadian TB Paru di wilayah kerja Puskesmas Bolangitang

b. Analisa hubungan kemiskinan dengan kejadian TB di wilayah kerja Puskesmas Bolangitang Tabel 5

Hubungan Kemisikinan dengan TB Paru 
Jurnal Zaitun

Universitas Muhammadiyah Gorontalo

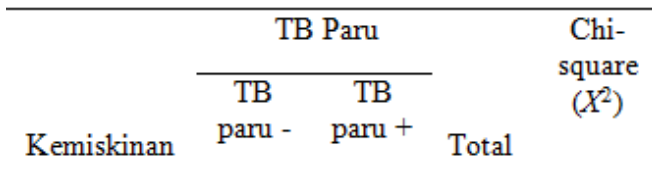

Alpha

$(\alpha)$

\begin{tabular}{ccccc}
\hline $\begin{array}{c}\text { Prasejahtera } \\
1\end{array}$ & 0 & 22 & 22 & \\
$\begin{array}{cccc}\text { Prasejahtera } \\
2\end{array}$ & 10 & 6 & 16 & \\
\cline { 1 - 3 } Total & 10 & 28 & 38 & 0.000
\end{tabular}

Sumber : Data Primer 2016

Dapat dijelaskan bahwa dari 38 responden paling banyak adalah responden dengan tingkat kemiskinan prasejahtera 1 dan mengalami TB paru + yang berjumlah 22 orang. Dari hasil analisa statistik didapatkan nilai chi square sebesar 18.661 dengan tingkat signifikan $\alpha=0.000<0.05$ artinya bahwa terdapat hubungan antara pra sejahtera 1 dengan kejadian TB paru. Sehingga tolak $\mathrm{H}_{0}$ dan menerima $\mathrm{H}_{1}$ yakni terdapat hubungan antara kemiskinan dengan kejadian TB Paru di wilayah kerja Puskesmas Bolangitang

c. Analisa hubungan lingkungan dengan kejadian TB di wilayah kerja Puskesmas Bolangitang Kabupaten Bolaang Mongodow Utara tahun 2014

Tabel 4.6

Hubungan Lingkungan dengan TB Paru

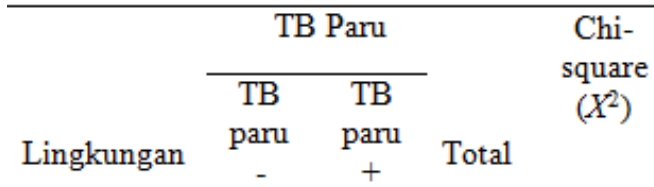

Alpha

$(\alpha)$

\begin{tabular}{ccccc}
\hline $\begin{array}{c}\text { Lingkungan } \\
\text { kotor }\end{array}$ & 0 & 21 & 21 & \\
\cline { 1 - 3 } $\begin{array}{c}\text { Lingkungan } \\
\text { bersih }\end{array}$ & 10 & 7 & 17 & 0.765 \\
\cline { 1 - 3 } Total & 10 & 28 & 38 & 0.000
\end{tabular}

Sumber : Data Primer 2016

Mencermati data pada tabel 6 diketahui bahwa dari 38 responden paling banyak adalah responden yang tinggal di lingkungan kotor dan mengalami TB paru + yang berjumlah 21 orang. Dari hasil analisa statistik didapatkan nilai chi square sebesar 16.765 dengan tingkat signifikan $\alpha=$ $0.000<0.05$ artinya bahwa terdapat hubungan antara lingkungan dengan kejadian TB paru. Sehingga tolak $\mathrm{H}_{0}$ dan menerima $\mathrm{H}_{1}$ yakni terdapat hubungan antara lingkungan dengan kejadian TB Paru di wilayah kerja Puskesmas Bolangitang

\section{PEMBAHASAN}

Hubungan umur dengan kejadian TB di wilayah kerja Puskesmas Bolangitang Kabupaten Bolaang Mongodow Utara tahun 2014. Berdasarkan tabel data univariat menunjukkan bahwa dari 38 responden sebagian besar berumur produktif $<55$ tahun yakni berjumlah 28 orang $(74 \%)$ sedangkan yang berusia $>55$ tahun berjumlah 10 orang (26\%). Dari hasil 
analisa diperoleh nilai chi square 38.000 dengan alpha $\alpha=0.000<0.05$ artinya bahwa terdapat hubungan antara umur dengan kejadian TB paru. Sehingga tolak $\mathrm{H}_{0}$ dan menerima $\mathrm{H}_{1}$ yakni terdapat hubungan antara umur dengan kejadian TB Paru di wilayah kerja Puskesmas Bolangitang Umur merupakan faktor yang berhubungan dengan kejadian kasus TB Paru + dan yang paling banyak berusia $<55$ tahun. Hasil penelitian ini sejalan dengan penjelasan Depkes. RI (2001) bahwa variabel umur berperan dalam kejadian penyakit tuberkulosis paru. Risiko untuk mendapatkan tuberkulosis paru dapat dikatakan seperti halnya kurva normal terbalik, yakni tinggi ketika awalnya, menurun karena di atas 2 (dua) tahun hingga dewasa memliki daya tahan terhadap tuberkulosis paru dengan baik. Puncaknya tentu dewasa muda dan menurun kembali ketika seseorang atau kelompok menjelang usia tua.

Dijelaskan pula oleh Tambayong (2000) faktor penyebab TB Paru adalah umur, beberapa faktor resiko penularan penyakit tuberkulosis di Amerika yaitu umur, jenis kelamin, ras, asal negara bagian, serta infeksi AIDS. Dari hasil penelitian yang dilaksanakan di New York pada panti penampungan orang - orang gelandangan menunjukkan bahwa kemungkinan mendapat infeksi tuberkulosis aktif meningkat secara bermakna sesuai dengan umur. Insiden tertinggi tuberkulosis paru biasanya mengenai usia dewasa muda. Di Indonesia diperkirakan $75 \%$ penderita TB Paru adalah kelompok usia produktif yaitu 15-50 tahun.
Hasil penelitian ini sejalan dengan penelitian yang dilakukan oleh Irawan (2010) yang berjudul Faktor yang Berhubungan dengan Kejadian TB Paru di RSUP H. Adam Malik. Dari hasil penelitian menunjukkan bahwa umur responden berhubungan dengan kejadian TB paru dan kelompok umur terbanyak 55 - 60 tahun dengan persentase $52.9 \%$.

Hubungan kemiskinan dengan kejadian TB di wilayah kerja Puskesmas Bolangitang.

Dari 38 responden yang paling banyak adalah responden yang memiliki tingkat kemisikinan prasejahtera 1 yang berjumlah 22 orang $(58 \%)$ dan responden dengan tingkat kemiskinan pra sejahtera 2 berjumlah 16 orang (42\%). Hasil analisa statistik didapatkan nilai chi square sebesar 18.661 dengan tingkat signifikan $\alpha=$ $0.000<0.05$ artinya bahwa terdapat hubungan antara kemiskinan dengan kejadian TB paru.

Status ekonomi atau tingkat kemiskinan berhubungan dengan penyakit TB paru. Akibat penyakit TB paru penderita menjadi tidak produktif atau produktifitasnya menurun sehingga ekonomi keluarga terganggu bahkan kehilangan pendapatan dan sebaliknya, dalam kondisi kemiskinan, masyarakat rawan terkena penyakit menular termasuk TB paru.

Menurut Darmanto (2007) bahwa kondisi kemiskinan berkaitan erat dengan pendidikan, keadaan sanitasi lingkungan, gizi dan akses terhadap pelayanan kesehatan. Penurunan pendapatan dapat menyebabkan kurangnya kemampuan daya beli dalam memenuhi konsumsi makanan 
sehingga akan berpengaruh terhadap status gizi. Apabila status gizi buruk maka akan menyebabkan kekebalan tubuh yang menurun sehingga memudahkan terkena infeksi TB Paru. Faktor ekonomi, dalam hal ini kemiskinan pada umumnya berkaitan erat dengan berbagai masalah kesehatan karena ketidakmampuan dalam mengatasi masalah kesehatan. Masalahkemiskinan akan sangat mengurangi kemampuan masyarakat untuk memenuhi kebutuhan gizi, pemukiman dan lingkungan sehat, jelas semua ini akan mudah menumbuhkan penyakit tuberkulosis. Dijelaskan pula oleh WHO dalam Depkes (2003) menyebutkan 90\% penderita tuberkulosis paru di dunia menyerang kelompok dengan sosial ekonomi lemah atau miskin

Hasil penelitian ini sejalan dengan penelitian terdahulu yang pernah dilakukan oleh Ni Yoman Kristina (2008) yang berjudul "Hubungan antara faktor kepadatan, kemiskinan, status penduduk pendatang dan jarak sarana pelayanan dengan kejadian TBC di Kota Denpasar". Dari hasil penelitian menunjukkan bahwa kemiskinan berhubungan dengan kemisikinan dengan tingkat signifikan $0.0004<0.05$. Artinya kemiskinan berhubungan dengan kejadian TBC di Kota Denpasar.

Hubungan lingkungan dengan kejadian TB di wilayah kerja Puskesmas Bolangitang Dari 38 responden paling banyak mengalami TB paru + yakni berjumlah 28 orang (74\%) sedangkan yang mengidap TB paru - berjumlah 10 orang $(26 \%)$. Dari hasil analisa statistik didapatkan nilai chi square sebesar 16.765 dengan tingkat signifikan $\alpha=0.000<0.05$ artinya bahwa terdapat hubungan antara kemiskinan dengan kejadian TB paru. Lingkungan berpengaruh dengan kejadian TB karena kondisi lingkugan seperti kepadatan penghunian rumah, kelembapan rumah, ventilasi, pencahayaan sinar matahari, lantai rumah dan dinding serta lingkungan yang kotor berhubungan dengan kejadian TB.

Menurut Tambayong (2000) bahwa kondisi lingkungan tempat tinggal dapat menjadi salah satu faktor resiko penularan penyakit TB Paru. Atap, dinding dan lantai dapat menjadi tempat perkembang biakan kuman. Lantai dan dinding yag sulit dibersihkan akan menyebabkan penumpukan debu, sehingga akan dijadikan sebagai media yang baik bagi berkembangbiaknya kuman Mycrobacterium tuberculosis.

Seserorang yang tinggal di rumah yang bersih juga kemungkinannya bisa terkena penyakit TBC, karena seseorang tidak selamanya tinggal di dalam rumahnya saja, bisa saja suatu saat ia berada di tempat lain seperti di kantor, bus, pasar dan tempat lain yang belum tentu terbebas dari kuman TBC. Namun hidup di lingkungan yang bersih bisa memperkecil resiko terjadinya TBC (Http:/www.medicastore.2012).

Dijelaskan pula oleh Notoatmodjo (2003) bahwa lingkungan rumah merupakan salah satu faktor yang memberikan pengaruh besar terhadap status kesehatan penghuninya.

Hasil penelitian ini sejalan dengan penelitian terdahulu yang dilakukan 
oleh Siti Fatimah (2008) yang berjudul "Hubungan Faktor Kesehatan Lingkungan Rumah Dengan Kejadian TB Paru di Kabupaten Cilacap Tahun 2008". Dari hasil penelitian disimpulkan bahwa terdapat hubungan antara faktor kesehatan lingkungan rumah dengan kejadian tuberkulosis paru di Kabupaten Cilacap.

\section{KESIMPULAN dan SARAN Kesimpulan}

1. Dari 38 responden paling banyak mengalami TB paru + yakni berjumlah 28 orang (74\%) sedangkan yang mengidap TB paru - berjumlah 10 orang (26\%). Dari 38 responden sebagian besar berumur produktif < 55 tahun yakni berjumlah 28 orang $(74 \%)$ sedangkan yang berusia $>55$ tahun berjumlah 10 orang (26\%). Dari 38 responden yang paling banyak adalah prasejahtera 1 yang berjumlah 22 orang $(58 \%)$ dan responden dengan tingkat pra sejahtera 2 berjumlah 16 orang (42\%). Dari 38 responden paling banyak mengalami TB paru + yakni berjumlah 28 orang $(74 \%)$ sedangkan yang mengidap TB paru - berjumlah 10 orang (26\%).

2. Umur berhubungan dengan kejadian TB Paru di wilayah kerja Puskesmas Bolangitang Kabupaten Bolaang Mongodow Utara tahun 2014 yang dibuktikan oleh nilai chi square 38.000 dengan alpha $\alpha=0.000<0.05$ artinya bahwa terdapat hubungan antara umur dengan kejadian TB paru.

3. Kemiskinan berhubungan dengan kejadian TB Paru di wilayah kerja
Puskesmas Bolangitang Kabupaten Bolaang Mongodow Utara tahun 2014 yang ditunjukkan oleh nilai chi square sebesar 18.661 dengan tingkat signifikan $\alpha=0.000<0.05$ artinya bahwa terdapat hubungan antara kemiskinan dengan kejadian TB paru.

4. Lingkungan berhubungan dengan kejadian TB Paru di wilayah kerja Puskesmas Bolangitang Kabupaten Bolaang Mongodow Utara tahun 2014 yang dibuktikan oleh nilai signifikan $\alpha=0.000<0.05$ artinya bahwa terdapat hubungan antara kemiskinan dengan kejadian TB paru.

\section{Saran}

Diharapkan masyarakat dapat mencegah terjadinya TB paru dengan menjaga kondisi lingkungan, meningkatkan taraf hidup dan bagi masyarakat yang berumur tidak produktif dapat memeriksakan kesehatan secara rutin agar tidak mengalami kekambuhan TB paru.

\section{DAFTAR PUSTAKA}

Aditama dkk, 2008. Pedoman

Penanggulangan Tuberkulosis

di Tempat Kerja (Workplace).

Jakarta : Departemen

Kesehatan RI

Akbar. 2010. Faktor-Faktor yang Berhubungan Dengan Kejadian Tbc Paru di Wilayah Kerja Puskesmas Bolangitang Kabupaten Bolaang Mongondow Utara. Gorontalo : Universitas Gorontalo 
Jurnal Zaitun

Universitas Muhammadiyah Gorontalo

Depkes RI. 2008. Pedoman Penanggulangan Tuberkulosis. Edisi Kedua, cetakan Pertama. Jakarta : Depkes RI

Dinas Kesehatan Kabupaten, 2012. Data Penderita tuberkulosis, Bolaang Mongondow Utara

Fahdhienie, F. 2011. Case Distribution of Pulmonary Tuberculosis and Risk Factors in Gunungkidul. Yokyakarta : Universitas Gadjah Mada

Fatimah, S. 2008. Faktor Kesehatan Lingkungan Rumah yang Berhubungan dengan Kejadian TB Paru di Kabupaten Cilacap (Kecamatan : Sidareja, Cipari, Kedungreja, Patimuan, Gandrungmangu, Bantarsari). Semarang : Universitas Diponegoro

Handayani, 2009, Gambaran Asupan Zat Gizi Makro dan Status Gizi pada Penderita Tuberkulosis Paru Rawat Inap di RSUD $d r$. Moewardi Surakarta : Universitas Muhammadiyah Surakarta

Kepmenkes RI. 2009. Pedoman Penanggulangan Tuberkulosis. Nomor 364/Menkes/SK/VIII/1999

Mustangin, 2008. Hubungan Pengetahuan dan Sikap Orang Tua tentang Tuberkulosis Paru dengan Kejadian TB pada
Anak di Balai Besar Kesehatan Paru Masyarakat (BBKPM). Surakarta :Universitas Muhammadiyah Surakarta

Notoatmodjo. 2002. Metode Penelitian Kesehatan.Jakarta: Rineka Cipta.

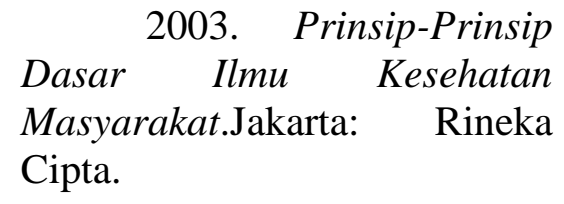

Oktaviani, V. 2009.Hubungan antara sanitasi fisik rumah dengan kejadian Infeksi saluran pernafasan atas (ispa) pada balitaDi desa cepogo kecamatan cepogoKabupaten boyolali.Surakarta : Universitas Muhammadiyah Surakarta

Rakhmawati dkk, 2008.Hubungan Status Gizi, Imunisasi \& Riwayat Kontak dengan Kejadian Tuberkulosis pada Anak di Wilayah Kerja Puskessmass Ciawi Kabupaten Tasikmalaya.Bandung Universitas Padjajaran

Puskesmas Buroko, 2012, Register Puskesmas Boroko, Boroko

Soejadi, T.B. 2008. Analisis Faktorfaktor yang Mempengaruhi Kejadian Kasus TBC Paru.Medan : Jurnal Ilmiah PANNED

Sugiyono. 2010. Metode Penelitian Kuantitatif, Kualitatif dan $R \& D$. Bandung: Alfabeta. 
Jurnal Zaitun

Universitas Muhammadiyah Gorontalo 